\title{
Training, Inclusion, and Behaviour: Effect on Student-Teacher and Student-SEA Relationships for Students with Autism Spectrum Disorders
}

\author{
Jacqueline A. Brown \\ Kent Mclntosh \\ University of British Columbia
}

\begin{abstract}
Little is known about factors that affect teacher and special educational assistants' (SEA) relationships with students with Autism Spectrum Disorders (ASD). In this study, participants were 15 students with ASD receiving inclusive education in Kindergarten through Grade 3, their classroom teachers, and SEAs. Teachers and SEAs completed rating scales assessing problem behaviour and the quality of student-teacher and student-SEA relationships. Results showed that the level of problem behaviour and percent of time receiving the general education curriculum (i.e., not a modified curriculum) significantly predicted the studentteacher relationship, but not the student-SEA relationship. Training in ASD did not significantly predict the student-teacher or student-SEA relationship.
\end{abstract}

Autism spectrum disorders (ASD) are lifelong developmental disabilities, with their core difficulties being apparent early in a child's life. According to the American Psychiatric Association (2000), the primary impairments in ASD consist of deficits in reciprocal social interaction; social communication; and the presence of stereotyped behaviour, interests, and activities. Within the school setting, some students with ASD have been shown to withdraw from their teacher or peers for an extended period of time without being noticed (Ochs, Kremer-Sadlik, Soloman, \& Sirota, 2001).

Along with other factors, such as cognitive levels and communication skills, this lack of social engagement with other individuals can interfere with the percent of time students with ASD are placed within the general education classroom (i.e., level of inclusion; Goodman \& Williams, 2007). When placed in the classroom, some children tend to interact more with teachers than peers (Donnellan, Mesaros, \& Anderson, 1984). As a result, interactions between students and teachers are important targets for social growth. Hence, outcomes may be enhanced if teachers have knowledge and skills in instructional strategies for increasing social involvement (Goodman \& Williams, 2007; Harrower \& Dunlap, 2001). 
Interactions between students and teachers can influence short term student outcomes, such as the likelihood of problem behaviour, as well as long term outcomes, such as academic achievement and the degree of independent functioning (Hamre \& Pianta, 2001; Hughes \& Kwok, 2007). Although there has been a substantial research focus on student-teacher interactions and student outcomes in general, there is limited research that examines relationships between classroom teachers and students with ASD (Robertson, Chamberlain, \& Kasari, 2003). Because the student-teacher relationship may be related to both the percent of time students spend in the general education classroom and their long term outcomes (Cook, 2004), it is important to understand what variables contribute to these relationships and how research in this area may relate to students with ASD.

\section{Student-Teacher Relationships}

Positive student-teacher relationships are related to student social behaviour and emotional self-regulation. Students with higher quality student-teacher relationships tend to have higher levels of social and emotional adjustment (Murray \& Greenberg, 2000). Furthermore, lower quality student-teacher relationships have been associated with higher levels of externalizing, internalizing, and attention problems (McIntyre, Blacher, \& Baker, 2006).

Howes (2000) examined the relations between student-teacher relationships and the social emotional climate in preschool and students' adaptive and maladaptive behaviours in Grade 2. Students who had positive relationships with their teachers and peers in preschool were more likely to display prosocial behaviour in Grade 2 and less likely to display maladaptive behaviours, such as aggression, disruption, and social withdrawal. Similarly, Baker (2006) found that positive student-teacher relationships were related to more positive work habits and social skills for typically-developing students.

Although there has been much research examining student-teacher relationships for general education students, little research has examined student-teacher relationships for students with ASD. Robertson and colleagues (2003) examined student-teacher relationships, problem behaviour, the presence of a special educational assistant (SEA; a paraprofessional providing one-to-one support), and level of social inclusion. Participants included 12 students with autism, 6 SEAs, and 12 general education teachers. Results of this study showed that none of the classroom teachers had formal training in special education, $83 \%$ had never taught a student with ASD, and 50\% had never taught a student with special needs. Furthermore, problem behaviours (e.g., inattention and hyperactivity/impulsivity) were associated with a conflictual studentteacher relationship, with inattention negatively correlated with ratings of closeness.

\section{Problem Behaviour and Student-Teacher Relationships}

Negative student-teacher relationships have been associated with future increases in disruptive behaviour. Ladd and Burgess (2001) found a significant positive correlation between conflictual student-teacher relationships in the fall of Kindergarten and student aggression in the spring of Grade 1. Furthermore, higher scores of student-teacher conflict predicted increases in student misconduct and attention problems.

Conflictual student-teacher relationships may also be related to teacher attempts to control student behaviour, which may impede efforts to foster a positive school climate (Hamre \& Pianta, 2001). These researchers found that student-teacher relationships predicted behavioural outcomes through late elementary school and early middle school, especially for students at-risk for developing problem behaviour. Although positive student-teacher relationships were also 
significantly correlated with academic outcomes, negative relationships with teachers had a stronger effect on future disruptive behaviour.

Students with ASD often lack the skills to display appropriate social interactions and some may engage in problem behaviour to serve a social function, such as to obtain student-teacher interactions (Macintosh \& Dissanayake, 2006). Because students who misbehave face an increased risk of isolation from educational settings (Horner, Carr, Strain, Todd, \& Reed, 2002), problem behaviours may be related to negative outcomes for those who are already at greater risk for social exclusion. Macintosh and Dissanayake suggested that because students with ASD have social impairments, they may benefit from empirically validated interventions to teach social skills through modeling, prompting, feedback, and reinforcement. Although many researchers have examined problem behaviour and student-teacher relationships with general education students (e.g., Hamre \& Pianta, 2001), limited studies have examined this combination for students with ASD.

\section{Presence of an SEA and Student-Teacher Relationships}

The presence of an SEA can also lead to decreased student-teacher interactions. SEAs typically provide individual assistance to students with special needs within the classroom. One study found that classroom teachers were less engaged with their students when an SEA was present, with interactions limited to greetings, farewells, and occasional praise (Giangreco, Edelman, Luiselli, \& MacFarland, 1997). Results of this study also showed that SEAs often inappropriately took the primary role in making instructional decisions for these students. The results of another study (Giangreco, Broer, \& Edelman, 2001) showed that teachers were less engaged when the SEA was responsible for the student, but more engaged teachers were more knowledgeable about the student's academic functioning, learning outcomes, and curricular activities.

SEAs are often expected to take control of student instruction, yet they rarely have the same level of educational training as classroom teachers. Marks, Schrader, and Levine (1999) provided evidence that an SEA's level of training and experience to address problem behaviour may decrease the teacher's level of responsibility for the student. Furthermore, the presence of SEAs may influence the behaviour and academic performance of students with ASD (Young \& Simpson, 1997). In Young and Simpson's (1997) study, SEAs initiated limited interactions with their students with ASD, and these interactions were primarily verbal, despite the fact that these students often struggle with verbal directions. They highlighted the importance of providing SEAs with the training to both support the needs of students with ASD and work collaboratively with classroom teachers.

\section{Training in ASD and Teacher Perceptions}

Many general education teachers report a lack of experience and preparedness in teaching students with ASD and other disabilities. This lack of experience may influence their attitudes both toward students with special needs and their placement in general education classrooms (Cook, Tankersley, Cook, \& Landrum, 2000; McGregor \& Campbell, 2001). Teachers with further training in special education or experience teaching students with ASD and collaborating with special education personnel are more likely to have positive perceptions of these students and report beliefs that students with ASD should be integrated into mainstream classrooms (McGregor \& Campbell, 2001). 
The quality and quantity of training on teachers' perceptions of students with ASD has also been examined. Some researchers emphasize that it is the quality of training that is important (Cook et al., 2000), whereas other researchers feel that attending a one or two day workshop on ASD is not sufficient, as it may be limited to particular topics and focus specifically on one area of functioning (Scheuermann, Webber, \& Boutot, 2003). These researchers recommended that teachers receive instruction in behaviour management and specific skills to teach students with ASD. Because of the questions that remain with both teacher and SEA training, more research is needed to further examine training in ASD for both professionals and how this training may influence student-teacher relationships.

\section{The Present Study}

Due to this dearth of research examining problem behaviour and training in ASD, the present study built upon the results of Robertson and colleagues (2003). Student levels of problem behaviour, training in ASD, and the percent of time the student received the general education curriculum were all examined. Unlike the Robertson study, the present study assessed both the student-teacher and student-SEA relationship, as student relationships with other school professionals have not been assessed. Because students with ASD have core impairments in developing appropriate peer relationships and engaging in social reciprocity (American Psychiatric Association, 2000), it is important to consider their relationships with others when seeking to improve their classroom functioning.

The main objective was to identify key variables that are associated with student-teacher relationships to determine which factors can be targeted to improve these relationships. A second objective was to determine whether the percent of time the student receives the general education curriculum is related to the student-teacher and student-SEA relationship. Some previous research findings indicate that the presence of an SEA increases positive ratings by teachers (Cook, 2004), and other studies show that it may decrease the quality of the student-teacher relationship (Giangreco et al., 1997; Marks et al., 1999). Although Robertson and colleagues (2003) found a moderate association between social inclusion, as rated by the student's peers, and the student-teacher relationship, research has not examined how the percent of time receiving the general education curriculum (i.e., not a modified curriculum) affects the student-teacher relationship.

\section{Participants}

\section{Method}

The sample consisted of 15 boys with ASD in general education classrooms in Kindergarten through Grade 3, their classroom teachers $(N=15)$, and SEAs $(N=15)$ in four school districts in British Columbia. Student demographic data were reported by teachers and SEAs. The mean student age was 7 years 6 months, with students ranging from 6 years 1 month to 9 years 6 months. This age group was chosen so that variables that influence student-teacher relationships can be identified for early intervention purposes to improve outcomes for these students. The ethnic background of the students was 53.33\% Caucasian Canadian, 33.33\% Asian Canadian, and $13.33 \%$ Unidentified. English was a second language for 5 of the 15 students. Ten students $(67 \%)$ participated in the same curriculum as their classmates $50 \%$ or less of the school day, and five $(33 \%)$ participated $51 \%$ or more of the day.

Participants were recruited through district Autism support teams. Students were included in the study if they were placed in a general education classroom full time and met educational 
criterion for ASD. These criteria include a qualified specialist's diagnosis of an ASD and evidence that the disorder adversely affected students' educational performance. Although students who participated in the same curriculum $50 \%$ or less of the day were still placed in the general education classroom, they received different work from the rest of the students during the majority of the school day.

The number of years of teaching experience for teachers ranged from 3 to 30 years $(M=$ 14.87 years, $S D=8.32$ ) and the number of years teaching students with ASD ranged from 1 to 17 years $(M=5.97$ years, $S D=5.41)$. Fifty-three percent of these teachers received ASD pre-service training. When examining the specific type of training received, $57 \%$ indicated that ASD was covered in one course, $21 \%$ indicated that it was covered extensively in one course, and $14 \%$ noted that it was the sole focus of one course. All teachers reported that the SEA worked with the student $51 \%$ or more of the school day, with the majority indicating that the student received at least $76 \%$ of SEA support.

The number of years working as an SEA ranged from 2 to 21 years $(M=8.27$ years, $S D=$ 5.38) and the number of years SEAs worked with students with ASD ranged from 1 to 20 years $(M=7.20$ years, $S D=5.21)$. Eighty-seven percent of the SEAs received pre-service ASD training. When examining the specific type of training, $86 \%$ reported that it was both covered and covered exclusively in one course, and $71 \%$ indicated that it was the sole focus of one course.

\section{Measures}

Student-teacher relationships. Student-teacher relationships were measured using the Student-Teacher Relationship Scale (STRS; Pianta, 2001). The STRS is a 28-item self report questionnaire that assesses teacher perceptions of their relationship with an individual student. Three dimensions of the relationship, conflict, closeness, and dependency, are measured. The conflict subscale examines how much a teacher perceives his or her relationship with a student as being negative and conflictual, whereas the closeness subscale measures the degree to which a teacher experiences warmth, affection, and open communication with a student. Finally, the dependency subscale measures the degree to which a teacher perceives a student as being overly dependent. The STRS total scale was used in the current study, measuring the degree to which a teacher perceives his or her overall relationship with a student as being positive and effective. Higher scores on this scale correspond to lower levels of conflict and dependency and higher levels of closeness. These dimensions are measured through a 5-point Likert scale format. In the STRS, raw scores are converted to percentiles. A raw score of 102 is at the $25^{\text {th }}$ percentile, a score of 116 is at the $50^{\text {th }}$ percentile, and a score of 125 is at the $75^{\text {th }}$ percentile.

Psychometric properties indicate that the STRS total scale correlates with concurrent and future behaviour problems and academic skills. Adequate to strong associations (ranging from .29 for the dependency scale to -.72 for the STRS total scale) were found between Kindergarten STRS scores and concurrent behavioural problem ratings on the Teacher-Child Rating Scale (Hightower et al., 1986), a measure of child behavioural problems and school competencies. An adequate degree of association (ranging from .30 for the dependency scale to -.56 for the STRS total scale) was also found between Kindergarten STRS scores and behavioural problem ratings in Grade 1 on the Teacher-Child Rating Scale (Pianta, Steinberg, \& Rollins, 1995). Significant relations have also been found between Kindergarten STRS scores and teacher's ratings of work habits through Grade 8 (Hamre \& Pianta, 2001). Finally, research has shown that the STRS measures different constructs than other problem behaviour and social competence measures, as correlations between the STRS and other measures do not exceed .58 (Hamre \& Pianta, 2001). 
Problem behaviour. Problem behaviour was measured using the Teacher Rating Scale of the Behaviour Assessment System for Children, Second Edition (BASC-2, Child version; Reynolds \& Kamphaus, 2004). The BASC-2 is a multimethod, multidimensional system that is used to rate the behaviour of school-aged children aged 6 through 11. This study used the Behavioural Symptoms Index (BSI), an index of overall problem behaviour that includes internalizing, externalizing, and school problems composite scales and the atypicality and withdrawal subscales, which includes 90 items included within this index. The BASC-2 provides T-scores with a mean of 50 and a standard deviation of 10. BASC-2 BSI T-scores are classified according to the ranges, Average: 41-59, At-Risk: 60-69, and Clinically Significant: $\geq 70$. Psychometric properties indicate that the internal consistency of the BSI is excellent (.96 to .97), and the adjusted test-retest reliability is .90 (Reynolds \& Kamphaus, 2004).

Training in ASD. Training in ASD was measured using teacher and special educational assistant questionnaires created for the present study. Based on their responses, teachers and SEAs were labeled as having pre-service training if they indicated that they had learned about ASD in their most recent degree and were included in one of two categories, pre-service or no pre-service training.

Percent of time receiving the general education curriculum. The percent of time receiving the general education curriculum was defined as the percent of the day the student participated in the same curriculum as the rest of the class (i.e., the exact same curriculum and not simply the same subject), possibly with SEA support. This definition was chosen due to the strong inclusion focus of the school districts from which the participants were recruited, with students both with and without significant challenges being included in the general education classroom. Consequently, these ratings helped distinguish students who were immersed in the classroom curriculum with their peers and teacher from those who received a more individualized program with the SEA. Teacher ratings of this percent were used according to one of four categories: $0-25 \%, 26-50 \%, 51-75 \%$, or $76-100 \%$. Because the responses were not normally distributed, they were dichotomized into two groups: (a) $50 \%$ or less or (b) $51 \%$ or more.

\section{Procedures and Analyses}

After consent was obtained, each classroom teacher and SEA independently completed the measures. Because English was a second language for five of the participants in this study, independent samples t-tests were first conducted to determine whether significant differences existed between English as a Second Language and native English speaking participants on the variables of interest. No significant differences were found between groups.

Coefficient alpha was computed to indicate internal consistency for combined teacher and SEA responses on the STRS total scale and the BASC-2 BSI. Internal consistency was poor (Nunnally \& Bernstein, 1994) for both the STRS total scale (.55) and the BASC-2 BSI composite (.40). Furthermore, the internal consistency for each of the three STRS dimension scores was also poor $(\mathrm{STRS}$ conflict $=.34, \mathrm{STRS}$ closeness $=.51, \mathrm{STRS}$ dependency $=.14)$.

Multiple regression analyses were conducted to determine whether teacher and SEA ratings of problem behaviour, percent of time receiving the general education curriculum, and teacher and SEA training in ASD significantly predicted the student-teacher or student-SEA relationship. Because previous research has shown that problem behaviour is strongly predictive of the student-teacher relationship (Robertson et al., 2003), block regression was used to test the relative influence of variables above and beyond problem behaviour. In the first model, teacher 
BSI ratings were entered. In the second model, student percent of time receiving the general education curriculum and teacher pre-service training in ASD were added. These analyses were then repeated with the SEA variables, but because of the lack of variability in SEA pre-service training, this predictor was not used. Analyses were conducted using SPSS version 14.

\section{Results}

Descriptive statistics for teacher and SEA ratings of the overall relationship on the STRS and ratings of student BASC-2 BSI are provided in Table 1. The three STRS dimension scores (conflict, closeness, and dependency) are also included in this table. Although the mean for BSI ratings was in the average category for both teacher and SEA ratings, three students were rated by teachers and four by SEAs as being in the at-risk category.

Table 1

Descriptive Statistics for Teacher and SEA

$B A S C-2$ and STRS Composites

\begin{tabular}{|c|c|c|c|}
\hline Measure & $M$ & $S D$ & Range \\
\hline \multicolumn{4}{|c|}{ Teacher Ratings } \\
\hline STRS Total & 104.87 & 8.56 & $90-124$ \\
\hline STRS Conflict & 24.13 & 5.99 & $13-34$ \\
\hline STRS Closeness & 34.47 & 5.72 & $26-42$ \\
\hline STRS Dependency & 7.40 & 2.59 & $5-14$ \\
\hline BASC-2 BSI & 53.67 & 6.38 & $45-67$ \\
\hline \multicolumn{4}{|c|}{ SEA Ratings } \\
\hline STRS Total & 107.07 & 9.98 & $86-121$ \\
\hline STRS Conflict & 22.67 & 6.48 & $16-35$ \\
\hline STRS Closeness & 40.47 & 6.23 & $29-49$ \\
\hline STRS Dependency & 12.73 & 3.94 & $6-21$ \\
\hline BASC-2 BSI & 57.53 & 4.63 & $48-64$ \\
\hline
\end{tabular}

\section{Variables Associated with Student-Teacher and Student-SEA Relationships}

Student-teacher relationship analyses. Block regression analyses revealed that teacher BSI ratings was significantly associated with the overall student-teacher relationship, $F$ $(1,13)=14.15, p<.01$, and explained $52 \%$ of the variance in the student-teacher relationship scores. When added to the model, the percent of time receiving the general education curriculum was also a significant predictor of the student-teacher relationship $(p<.01)$, although teacher pre-service training in ASD was not a significant predictor. Adding the percent of time receiving the general education curriculum and pre-service training in ASD to the model explained statistically significantly more variance in the total student-teacher relationship by adding a combined $28 \%$, even when controlling for teacher's BSI ratings, $F(2,11)=7.57, p<.01$. Results are displayed in Table 2.

Student-SEA relationship analyses. Block regression analyses were repeated with SEA ratings. Because all but two SEAs had pre-service training in ASD, this variable was excluded from the analyses. Results revealed that neither SEA BSI ratings nor the percent of time receiving the general education curriculum significantly predicted the overall student-SEA relationship. Results are displayed in Table 3. 
Table 2

Hierarchical Regressions Predicting the Total Student-Teacher Relationship

\begin{tabular}{|c|c|c|c|c|c|}
\hline & $b$ & $S E b$ & $\beta$ & $\mathrm{R}^{2}$ & $\Delta \mathrm{R}^{2}$ \\
\hline Model 1 & & & & .52 & $.52^{\star \star}$ \\
\hline Constant & 156.87 & 13.92 & & & \\
\hline BSI & -.97 & .26 & $-.72^{\star *}$ & & \\
\hline Model 2 & & & & .80 & $.28^{* *}$ \\
\hline Constant & 131.23 & 18.16 & & & \\
\hline $\mathrm{BSI}$ & -.72 & .21 & $-.53^{* *}$ & & \\
\hline Percent of time receiving curriculum & 10.55 & 2.71 & $.60^{* *}$ & & \\
\hline Pre-service training & 4.73 & 2.78 & .29 & & \\
\hline
\end{tabular}

Note. $\mathrm{BSI}=$ Behaviour Symptoms Index.

${ }^{* *} p<.01$

Table 3

Hierarchical Regressions Predicting the Total Student-SEA Relationship

\begin{tabular}{lrrrrr}
\hline & $b$ & $S E b$ & $\beta$ & $\mathrm{R}^{2}$ & $\Delta \mathrm{R}^{2}$ \\
\hline Model 1 & & & & .25 & .25 \\
$\quad$ Constant & 168.98 & 29.90 & & & \\
BSI & -1.08 & .52 & -.50 & & \\
& & & & & \\
Model 2 & & & & .30 & .05 \\
$\quad$ Constant & 145.14 & 38.78 & & & \\
BSI & -.79 & .60 & -.37 & & \\
Percent of time receiving curriculum & 5.49 & 5.67 & .27 & & \\
\hline Note. BSI = Behaviour Symptoms Index. & & & & &
\end{tabular}

Discussion

The goal of the present study was to examine how problem behaviour, percent of time receiving the general education curriculum, and training in ASD affect the student-teacher and student-SEA relationship. Results showed that the level of problem behaviour and percent of time receiving the general education curriculum significantly predicted the student-teacher relationship, but not the student-SEA relationship. Training in ASD did not significantly predict the student-teacher relationship.

Prior to the discussion of the findings, it is important to note that these results should be interpreted with caution due to the small sample size and understood within the context of an exploratory study. Consequently, these are preliminary findings that can contribute to future research and practices that aim to enhance educational opportunities for students with ASD.

\section{Variables Affecting Student-Teacher Relationships}

Problem behaviour. In the current study, problem behaviour was the strongest predictor of the student-teacher relationship. These findings are consistent with results of past research that problem behaviour negatively influences the student-teacher relationship for students with and without ASD (Hamre \& Pianta, 2001; Robertson et al., 2003). 
When considering these findings, the role of the classroom environment and characteristics of students with ASD could also be considered. Research findings have indicated that negative teacher reactions to student attempts to escape from the classroom environment may contribute to the formation of conflictual student-teacher relationships (Hamre \& Pianta, 2001). Furthermore, studies have also hypothesized that because of social deficits and stereotyped behaviour, students with ASD may be more likely to engage in problem behaviour to achieve social responses and escape from demands that may interrupt repetitive behaviours (Macintosh \& Dissanayake, 2006). Therefore, providing teachers with support in managing problem behaviour may be a promising avenue for improving student-teacher relationships.

Training in ASD. Although both problem behaviour and the percent of time receiving the general education curriculum were predictors of the student-teacher relationship, the teachers' pre-service training in ASD did not explain statistically significant unique variance in studentteacher relationships. Previous research has emphasized that training in ASD may be related to teacher perceptions of students with ASD and the percent of time they feel that those students should be included in the classroom (McGregor \& Campbell, 2001), yet a limited amount of research has examined the effect of training in ASD on the student-teacher relationship. Robertson and colleagues (2003) did not specifically examine this effect, but they noted that the teachers in their study frequently attended trainings in ASD with SEAs.

Because previous research has shown that training in ASD influences teacher perceptions and student inclusion within the classroom, it may be worthwhile to consider the role that training in ASD may play with respect to student problem behaviour and percent of time included in the general education curriculum. Although training in ASD did not predict the overall studentteacher relationship in the current study, it may have an indirect effect on this relationship. Both student problem behaviour and percent of time included in the general education curriculum predicted the overall student-teacher relationship, and these variables may have been affected by the teacher's training in ASD.

Despite the finding that this training did not significantly predict the overall relationship, teachers on average had 6 years of experience working with students with ASD. Compared to the study conducted by Robertson and colleagues (2003) where 83\% of teachers never taught a student with ASD, the teachers in the current study had more experience working with this population. Consequently, it is possible that this experience also contributes to the studentteacher relationship.

The preliminary findings of this exploratory study suggest that training in ASD may not be the most important predictor of the student-teacher relationship. Other factors, such as problem behaviour, may play a more direct role. Due to the dearth of research in this area and because of additional factors that need to be considered when examining the effect of ASD training on these relationships (e.g., years of experience), further studies should be conducted to examine the effect of training on these relationships with greater precision of measurement.

Percent of time receiving the general education curriculum. Findings showed that, even when accounting for the effects of problem behaviour, the percent of time the student received the general education curriculum significantly predicted the student-teacher relationship. However, it is also likely that higher degrees of receiving the general education curriculum are related to other variables. Despite the fact that the majority of students $(67 \%)$ in the current study participated in the same curriculum as the rest of the class $50 \%$ or less of the school day, one inclusion criterion was that they be placed in their classroom full time. 
Consequently, students in this sample may have had less impairment and higher levels of functioning than the overall population of students with ASD, which may limit generalization of these findings.

Previous research also found associations between student-teacher relationships and other forms of inclusion within the classroom. Findings from Robertson and colleagues (2003) indicated that lower levels of social inclusion were associated with higher levels of conflict and dependency in student-teacher relationships. Although inclusion was defined differently in each study, the results emphasize the importance of including students in the classroom and general education curriculum to increase their sense of belonging and foster positive relationships.

\section{Variables Affecting Student-SEA Relationships}

Although problem behaviour appears to affect the student-teacher relationship, it was not related to the student-SEA relationship. These findings indicate that in the present study, student problem behaviour and the percent of time receiving the general education curriculum may be more related to the relationship with the teacher than to that with the SEA. However, it is valuable to note that the SEA mean STRS and BSI ratings were slightly higher than those of teachers, indicating that although the regression results were not significant, they viewed their relationships with students as being more positive but also perceived more problem behaviours.

Various factors may account for these findings; however, one possibility may be that an SEA works with these students more intensively, through one to one support. Because they often receive training in preventing problem behaviour (Marks et al., 1999), the SEA may see a wide variety of behaviours and be less influenced by them. Furthermore, in this study, the majority of SEAs received previous ASD training. Consequently, their familiarity with ASD may have increased their understanding that students may use behaviour to communicate needs.

Although this is the first study to examine the role of problem behaviour in the studentSEA relationship, some previous findings have shown that teachers rate students with special needs more positively when an SEA is present (Cook, 2004), whereas other findings indicate that the presence of an SEA does not seem to influence their relationship (Robertson et al., 2003).

\section{Limitations and Future Research}

There are a number of limitations that should be considered when interpreting the results of this study. Most importantly, the small sample size and poor internal consistency of the STRS total scale and BSI composite should be taken into account when making implications for practice. As a result, less variability existed within the sample, in both SEA training within and outside the degree, as well as levels of student problem behaviour. Despite this limitation, it is important to note that the sample size was similar to previous research (Robertson et al., 2003). Furthermore, because of the small sample, the use of regression analysis, which typically requires a minimum of 10 participants per independent variable to ensure valid analysis, is also a limitation. As a result, the findings should be viewed with caution until results can be replicated with a larger sample.

Another key limitation is that some unmeasured variable may account for the relation between percent of time receiving the general education curriculum and the student-teacher relationship. For example, the current study did not examine the type or amount of SEA support provided or the quality or quantity of training in ASD for teachers and SEAs. Previous research has shown that both quality and quantity may affect teacher perceptions of students with ASD (Cook et al., 2000; Scheuermann et al., 2003). In addition, specific data were not collected 
regarding the students' level of functioning (e.g., severity of ASD and cognitive abilities). Future studies should explore how the classroom environment, instructional practices, as well as student behaviour and training in ASD influence teacher and SEA relationships with students across various levels of functioning. Along these same lines, research should also investigate whether student relationships with the teacher or SEA is more crucial for long-term outcomes, as well as student perceptions of their relationship with both of these professionals.

Finally, future research should also examine whether interventions implemented to target a student's problem behaviour affect the student-teacher relationship. Because the current study and past research has shown that problem behaviour effects the student-teacher relationship and that a problematic relationship can lead to further increases in a student's negative behaviour (Ladd \& Burgess, 2001), it is important that factors that improve or degrade these relationships be targeted.

\section{References}

American Psychiatric Association. (2000). Diagnostic and statistical manual of mental disorders (Revised 4th ed.). Washington, DC: Author.

Baker, J. A. (2006). Contributions of teacher-child relationships to positive school adjustment during elementary school. Journal of School Psychology, 44, 211-229. doi:10.1016/j.jsp.2006.02.002

Cook, B. G. (2004). Inclusive teachers' attitudes toward their students with disabilities: A replication and extension. The Elementary School Journal, 104, 307-320. Retrieved from http://www.jstor.org/action /showPublication?journalCode=elemschoj

Cook, B. G., Tankersley, M., Cook, L., \& Landrum, T. J. (2000). Teachers' attitudes toward their included students with disabilities. Exceptional Children, 67, 115-135. Retrieved from http://www.cec.sped.org /Content/NavigationMenu/Publications2/ExceptionalChildren/default.htm

Donnellan, A. M., Mesaros, R. A., \& Anderson, J. L. (1984). Teaching students with autism in natural environments: What educators need from researchers. The Journal of Special Education, 18, 505-522. doi: $10.1177 / 002246698401800407$

Giangreco, M. F., Broer, S. M., \& Edelman, S. W. (2001). Teacher engagement with students with disabilities: Differences between paraprofessional service delivery models. Journal of the Association for the Severely Handicapped, 26, 75-86. doi:10.2511/rpsd.26.2.75

Giangreco, M. F., Edelman, S. W., Luiselli, T. E., \& MacFarland, S. Z. C. (1997). Helping or hovering? Effects of instructional assistant proximity on students with disability. Exceptional Children, 64, 7-18. Retrieved from http://www.cec.sped.org/Content/NavigationMenu/Publications2/ExceptionalChildren /default.htm

Goodman, G., \& Williams, C. M. (2007). Interventions for increasing the academic engagement of students with autism spectrum disorders in inclusive classrooms. TEACHING Exceptional Children, 39, 53-61. Retrieved from http://www.cec.sped.org/Content/NavigationMenu/Publications2/TEACHINGExceptional Children/default.htm

Hamre, B. K., \& Pianta, R. C. (2001). Early teacher-child relationships and the trajectory of children's school outcomes through eighth grade. Child Development, 72, 625-638. Retrieved from http://www.wiley.com/ bw/journal.asp?ref $=0009-3920 \&$ site $=1$

Harrower, J. K., \& Dunlap, G. (2001). Including children with autism in general education settings: A review of effective strategies. Behaviour Modification, 25, 762-784. Retrieved from http://bmo.sagepub.com/

Hightower, D. A., Work, W. C., Cowen, E. L., Lotyczewski, B. S., Spinell, A. P., Guare, J. C., \& Rohrbeck, C. A. (1986). The teacher-child rating scale: A brief objective measure of elementary children's school problem behaviors and competencies. School Psychology Review, 15, 393-409. Retrieved from http://www.nasponline.org/publications/spr/index.aspx? vol=41\&issue $=3$

Horner, R. H., Carr, E. G., Strain, P. S., Todd, A. W., \& Reed, H. K. (2002). Problem behavior interventions for young children with autism: A research synthesis. Journal of Autism and Developmental Disorders, 32, 423-446. Retrieved from http://www.springer.com/psychology/child+\%26+school+psychology/journal $/ 10803$ 
Howes, C. (2000). Social-emotional classroom climate in child care, child-teacher relationships and children's second grade peer relations. Social Development, 9, 191-204. Retrieved from http://www.wiley.com/bw /journal.asp?ref=0961-205X

Hughes, J., \& Kwok, O. (2007). Influence of student-teacher and parent-teacher relationships on lower achieving readers' development and achievement in the primary grades. Journal of Educational Psychology, 99, 39-51. doi:10.1037/0022-0663.99.1.39

Ladd, G. W., \& Burgess, K. B. (2001). Do relational risks and protective factors moderate the linkages between childhood aggression and early psychological and school adjustment? Child Development, 72, 15791601. doi:10.1111/1467-8624.00366

Macintosh, K., \& Dissanayake, C. (2006). Social skills and problem behaviors in school aged children with high-functioning autism and Asperger's disorder. Journal of Autism and Developmental Disorders, 36, 1065-1076. doi:10.1007/s10803-006-0139-5

Marks, S. U., Schrader, C., \& Levine, M. (1999). Paraeducator experiences in inclusive settings: Helping, hovering, or holding their own? Exceptional Children, 65, 315-328. Retrieved from http://www.cec.sped .org/Content/NavigationMenu/Publications2/ExceptionalChildren/default.htm

McGregor, E., \& Campbell, E. (2001). The attitudes of teachers in Scotland to the integration of children with autism into mainstream schools. Autism, 5, 189-207. doi:10.1177/1362361301005002008

McIntyre, L. L., Blacher, J., \& Baker, B. L. (2006). The transition to school: Adaptation in young children with and without intellectual disability. Journal of Intellectual Disability Research, 50, 349-361. doi:10.1111 /j.1365-2788.2006.00783.x

Murray, C., \& Greenberg, M. T. (2000). Children's relationship with teachers and bonds with school: An investigation of patterns and correlates in middle childhood. Journal of School Psychology, 38, 423-445. doi:10.1016/S0022-4405(00)00034-0

Nunnally, J. C., \& Bernstein, I. H. (1994). Psychometric theory (3rd ed.). New York, NY: McGraw-Hill.

Ochs, E., Kremer-Sadlik, R., Soloman, O., \& Sirota, K. G. (2001). Inclusion as social practice: Views of children with autism. Social Development, 10,399-419. doi:10.1111/1467-9507.00172

Pianta, R. C. (2001). Student-Teacher Relationship Scale. Charlottesville, VA: Psychological Assessment Resources.

Pianta, R. C., Steinberg, M. S., \& Rollins, K. (1995). The first two years of school: Teacher-child relationships and deflections in children's classroom adjustment. Development and Psychology, 7, 297-312. doi:10 $.1017 / \mathrm{S} 0954579400006519$

Reynolds, C. R., \& Kamphaus, R. W. (2004). Behaviour Assessment System for Children: Second Edition. Circle Pines, MN: AGS.

Robertson, K., Chamberlain, B., \& Kasari, C. (2003). General education teachers' relationships with included students with autism. Journal of Autism and Developmental Disorders, 33, 123-130. doi:10.1023/A :1022979108096

Scheuermann, B., Webber, J., \& Boutot, A. (2003). Problems with personnel preparation in autism spectrum disorders. Focus on Autism and other Developmental Disabilities, 18, 197-206. doi:10.1177 $/ 10883576030180030801$

Young, B., \& Simpson, R. L. (1997). An examination of paraprofessional involvement in supporting inclusion of students with autism. Focus on Autism \& Other Developmental Disabilities, 97, 31-38. doi:10.1177 $/ 108835769701200104$

\section{Authors' Note}

Correspondence concerning this article should be addressed to Jacqueline A. Brown, Department of Counseling, Clinical, and School Psychology, University of California, Santa Barbara, Santa Barbara, CA, 93106-9490. E-mail: jbrown@education.ucsb.edu

Jacqueline A. Brown is now at the Department of Counseling, Clinical, and School Psychology at the University of California, Santa Barbara. Kent McIntosh is now at the Department of Special Education and Clinical Sciences at the University of Oregon. 